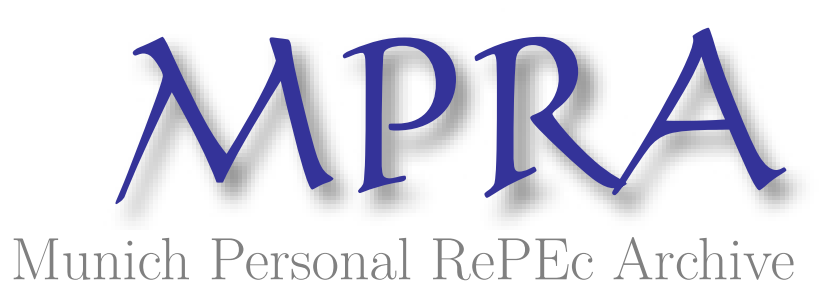

\title{
Multi-Product Firms, Product Scope, and the Policy of Export Tax Rebate
}

Han, Jianyu and Ma, Yeqing and Tan, Yong

Nanjing University

23 March 2014

Online at https://mpra.ub.uni-muenchen.de/54709/

MPRA Paper No. 54709, posted 23 Mar 2014 18:39 UTC 


\title{
Multi-Product Firms, Product Scope, and the Policy of Export Tax Rebate
}

\author{
Jian Han ${ }^{1, a}$, Yeqing $\mathrm{Ma}^{1, \mathrm{a}}$, Yong Tan ${ }^{1, \mathrm{a}, *}$ \\ ${ }^{a}$ Department of International Economics \& Trade, Nanjing University, \#22 Hankou \\ Road, Nanjing, P.R.China, 210093; Tel.:+86 2583621971
}

\begin{abstract}
Following Nocke and Yeaple (2012), we develop a model to explain how firms allocate their organizational capital to different products. Using the Chinese export and tax rebate data, we find that the reduction of export tax rebate causes contraction of product scope, and the less competitive products are more likely to be dropped.
\end{abstract}

Keywords:

Heterogenous Firms, Multi-product Firms, Product Scope, Export Tax

Rebate

JEL Classification: D22, F10, F14, L10

\section{Introduction}

Recent development in trade literature has shifted the focus to the multiproduct firms' performance in markets (Bernard et al., 2010, 2011; Eckel and Neary, 2006; Nocke and Yeaple, 2008, 2012; Manova and Zhang, 2012). Multi-product firms produce goods varying not only in quality, but also with different factor intensity (Song and Zhu, 2011). Bernard et al. (2010) find that the product factor intensities vary substantially for a multi-product firm and trade liberalization leads firms to drop their least successful products. Using Belgian manufacturing firm-level data, Fuss and Zhu (2012) show that about $30 \%$ of manufacturing firms produce goods in more than one 4-digit

\footnotetext{
* Corresponding author

Email address: yong.tan@nju.edu.cn (Yong Tan)
} 
NACE code industries, and trade liberalization results in faster TFP growth in comparative-advantage industries.

Our model illustrates the way how multi-product firms manage their product scope in response to the reduction of export tax rebate (ETR). In particular, firms allocate their organizational capital among different products. The product-level organizational capital, cost parameter, along with firm-level efficiency jointly determines the firm-product-level profit. The model suggests that the reduction of ETR causes product scope contraction, and the product of higher cost is more likely to be dropped. Our result is supported by the Chinese export data. Our result makes an additional contribution to the literature on multi-product firms and product-level heterogeneity in factor intensity ${ }^{1}$. To the best of our knowledge, similar studies are scant$\mathrm{y}$ in the literature. Two related studies are Nocke and Yeaple (2012) and Manova and Zhang (2012), who investigate the product scope adjustment of multi-product firms. However, the former neglects the heterogeneity in factor intensity across products, and the data limitation prevents them from further exploring the extensive margin changes; the latter introduces quality differentiation across products, but no explanations on why firms differentiate their product quality ex ante and drop their low quality product ex post are provided.

Our findings shed light on the determinant of extensive margin adjustment of export firms. It is found that the reduction of ETR forces export firms to drop their less competitive products. The extensive margin changes further increase the aggregate TFP of export firms.

\section{The Model}

Each firm decides its product scope, price, and export status. Following Nocke and Yeaple (2012), we assume that firms are heterogeneous in organizational capital and organizational efficiency. The production of each product requires labor, intermediate input and organizational capital. The more organizational capital is used in the production, the lower the marginal cost is, and the organizational efficiency determines the effectiveness of the organizational capital in reducing the marginal cost. The production of each

\footnotetext{
${ }^{1}$ We interpret product-level heterogeneity of factor intensity as product-level difference in comparative advantage.
} 
product needs a fixed cost in each period. A representative firm's production function for product $\omega$ is

$$
Q=\theta_{\omega} l^{\alpha_{\omega}} m^{1-\alpha_{\omega}}
$$

where $\theta_{\omega}=k_{\omega}^{\theta}$ is the productivity of product $\omega$, which is determined by the organizational capital $k_{\omega}$ allocating to product $\omega$, the firm specific organizational efficiency $\theta$. The total organizational capital is fixed at $K_{\theta}$ $\left(\sum_{\omega} k_{\omega}=K_{\theta}\right)$ for the firm. $l$ and $m$ are the labor and intermediate inputs, respectively. The parameter $\alpha_{\omega}$ is labor share. We assume that producing product $\omega$ requires at least one unit of organizational capital. The marginal cost of product $\omega$ is

$$
\begin{gathered}
c\left(k_{\omega}, \theta, z_{\omega}\right)= \begin{cases}z_{\omega} k_{\omega}^{-\theta}, & \text { if } k_{\omega} \geq 1 ; \\
\infty, & \text { if otherwise. }\end{cases} \\
z_{\omega}=w_{m}^{1-\alpha_{\omega}} w_{l}^{\alpha_{\omega}}\left[\left(\frac{1-\alpha_{\omega}}{\alpha_{\omega}}\right)^{\alpha_{\omega}}+\left(\frac{\alpha_{\omega}}{1-\alpha_{\omega}}\right)^{1-\alpha_{\omega}}\right]
\end{gathered}
$$

where $w_{l}$ and $w_{m}$ are prices for labor and intermediate input, respectively. $z_{\omega}$ is called cost parameter.

The consumers in the domestic and foreign markets have identical preference over varieties and take the CES form:

$$
U=\left[\int_{\Omega} x_{\omega}^{\frac{\sigma-1}{\sigma}} d \omega\right]^{\frac{\sigma}{\sigma-1}}
$$

where $x_{\omega}$ is the consumption of product $\omega$, and $\sigma>1$ is the substitution elasticity between products. We assume that the intermediate input can freely flow between the domestic and foreign markets, and so the two markets have the same intermediate price level. $L$ and $L^{*}$ are populations in the domestic and foreign markets, respectively. $w_{l} L$ and $w_{l}^{*} L^{*}$ are the corresponding aggregate incomes. The domestic and foreign demand functions generated by the preference are $x_{\omega}=A p(\omega)^{-\sigma}$ and $x_{\omega}^{*}=A^{*} p^{*}(\omega)^{-\sigma}$, where $p(\omega)$ (or $p^{*}(\omega)$ ) is the price in the domestic (or foreign) market, and $A$ (or $A^{*}$ ) is the corresponding residual demand in the domestic (or foreign) market which 
can be written as ${ }^{2}$

$$
\begin{aligned}
A & =\frac{(1-\beta) w_{l} L}{M\left[\int p\left(K_{\theta}, \theta, z\right)^{-(\sigma-1)} d G\left(K_{\theta}, \theta, z\right)\right]} \\
A^{*} & =\frac{\left(1-\beta^{*}\right) w_{l}^{*} L^{*}}{M^{*}\left[\int p^{*}\left(K_{\theta}, \theta, z\right)^{-(\sigma-1)} d G\left(K_{\theta}, \theta, z\right)\right]}
\end{aligned}
$$

The parameter $\beta\left(\beta^{*}\right)$ is the firm-level exit probability in the domestic (or foreign) market, and $M$ (or $M^{*}$ ) measures the number of potential entrants in the domestic (or foreign) market. The equilibrium is solved by backward induction.

The third stage: The representative firm chooses optimal prices in the domestic and foreign markets. That is, $p\left(k_{\omega}, \theta, z_{\omega}\right)=\frac{\sigma}{\sigma-1} c\left(k_{\omega}, \theta, z_{\omega}\right)$, $p^{*}\left(k_{\omega}, \theta, z_{\omega}\right)=\frac{\sigma}{\sigma-1} c^{*}\left(k_{\omega}, \theta, z_{\omega}\right)$ and $c^{*}\left(k_{\omega}, \theta, z_{\omega}\right)=\tau c\left(k_{\omega}, \theta, z_{\omega}\right)$ where $\tau$ is per unit iceberg trade cost, $\tau>1$.

The second stage: The firm decides the product scope. For $\omega$ to be produced, two conditions must be satisfied. First, the profit obtained from $\omega$ must be non-negative. The profit is given by

$$
\pi\left(k_{\omega}, \theta, z_{\omega}\right)=\frac{1}{\sigma-1}\left(\frac{\sigma}{\sigma-1}\right)^{-\sigma} \widetilde{A}\left(z_{\omega} k_{\omega}^{-\theta}\right)^{1-\sigma}-f_{\omega}
$$

where $\widetilde{A}$ is the aggregate residual demand in the domestic and foreign markets, and $f_{\omega}$ is the fixed production cost. Second, the marginal profits of all products $\omega$ must be identical. ${ }^{3}$ That is, $\frac{\partial \pi_{i}}{\partial k_{i}}=\frac{\partial \pi_{j}}{\partial k_{j}}$. Identical export decision among all products ${ }^{4}$ implies

$$
\frac{k_{i}}{k_{j}}=\left(\frac{\widetilde{z}_{j}}{\widetilde{z}_{i}}\right)^{\frac{1}{(\sigma-1) \theta-1}}
$$

where $\widetilde{z}_{i}=z_{i}^{1-\sigma}$. Therefore, a firm will allocate more organizational capital to products of lower cost parameter $z$.

${ }^{2} M /(1-\beta)$ (or $\left.M /\left(1-\beta^{*}\right)\right)$ is the mass of active firms in the domestic (or foreign) market. $\int p(k, \theta, z)^{-(\sigma-1)} d G\left(K_{\theta}, \theta, z\right)$ (or $\left.\int p^{*}(k, \theta, z)^{-(\sigma-1)} d G\left(K_{\theta}, \theta, z\right)\right)$ is the price index in the domestic (or foreign) market.

3 Our analysis is for firms with $\theta<\frac{1}{(\sigma-1)}$, which guarantees the concavity of the organizational capital. For firms with $\theta>\frac{1}{(\sigma-1)}$, it will only produce one product with the lowest cost parameter $z$.

${ }^{4}$ The entry cost is in the firm-level. 
Lemma 1. Suppose $z_{1}<z_{2}<\cdots<z_{N}$ and $N$ is the integrity part of $K_{\theta}$. The optimal product scope $N^{*}$ is given by

$$
N^{*}=\sup _{n \in\{1,2, \cdots, N\}}\left\{n: \widetilde{z}_{n} k_{n}^{[(\sigma-1) \theta-1]} \geq \widetilde{z}_{1} k_{1}^{[(\sigma-1) \theta-1]}\right\}
$$

where

$$
k_{n}=\frac{K_{\theta}}{Z}\left(\frac{\widetilde{z}_{1}}{\widetilde{z}_{n}}\right)^{\left[\frac{1}{[(\sigma-1) \theta-1]}\right.}, \quad Z=\sum_{n=1}^{N^{*}}\left(\frac{\widetilde{z}_{1}}{\widetilde{z}_{n}}\right)^{\frac{1}{[(\sigma-1) \theta-1]}}
$$

Lemma 2. If the mean of the fixed cost $f_{\omega}$ is the same for all $\omega \in \Omega$, then the product-level profit is negatively correlated to its cost parameter.

The first stage: The Firm makes the market entry decision. The free entry conditions are that the total discounted profit is equal to the fixed entry cost, i.e., $\int_{\Theta} V\left(K_{\theta}, \theta, z\right) d G\left(K_{\theta}, \theta, z\right)=F_{e}$ and $\int_{\Theta} V^{*}\left(K_{\theta}, \theta, z\right) d G\left(K_{\theta}, \theta, z\right)=$ $F_{e}^{*}$ for domestic and foreign markets, respectively. ${ }^{5}$

Lemma 3. $N^{*}$ is increasing in the total organizational capital stock $K$.

It implies that firms with more capital choose larger product scope.

Proposition 1. When $\tau$ rises, firms contract their product scope and hence the products of higher cost parameter are more likely to be dropped.

\section{The Impact of Export Tax Rebate on Firm's Product Scope}

The reduction of ETR is similar to an increase in trade cost, ${ }^{6}$ which reduces the export profit of each product, and further reduce firm-level total profit in foreign market. By proposition 1, the reduction of ETR causes firm-level product scope contraction and dropping of high cost products.

\footnotetext{
${ }^{5} V\left(K_{\theta}, \theta, z\right)=\sum_{\omega \in \Omega} \frac{\frac{1}{\sigma-1} A\left(z_{\omega} k_{\omega}^{-\theta}\right)^{(1-\sigma)}-f_{\omega}}{1-\beta} . V^{*}\left(K_{\theta}, \theta, z\right)=\sum_{\omega \in \Omega} \frac{\frac{1}{\sigma-1} A^{*}\left(z_{\omega} k_{\omega}^{-\theta}\right)^{(1-\sigma)}}{1-\beta^{*}}$.

${ }^{6}$ The reduction of ETR, hence the increase in trade cost, is unbalanced among different products
} 
Table 1: The Percentile of Firms Exporting Different Number of Products

\begin{tabular}{ccc}
\hline \hline Number of Products & $\begin{array}{c}\text { Percentile of } \\
\text { Ordinary Trade }\end{array}$ & $\begin{array}{c}\text { Percentile of } \\
\text { Full Sample }\end{array}$ \\
\hline 1 & $32.7 \%$ & $32.9 \%$ \\
2 & $16.9 \%$ & $17.1 \%$ \\
3 & $10.4 \%$ & $10.6 \%$ \\
4 & $7.0 \%$ & $7.2 \%$ \\
$>4$ & $32.9 \%$ & $32.1 \%$ \\
\hline
\end{tabular}

\subsection{Data}

We collect the data of ETR rate for the comprehensive Chinese export sectors in 2003 and 2004, and carefully merge the data with Chinese Customs data using the 8-digit HS code. In 2004, the ETR reform reduces the average ETR rate by about $30 \%$ to adjust the structure of export and the rebate payment default.

Table 1 shows that about $70 \%$ of firms ${ }^{7}$ export more than one product at 4-digit HS code level in the same year.

\subsection{Empirical Evidence}

The following regression is used to test the prediction of scope contraction in response to the reduction of ETR.

$$
\text { num_diff } f_{i}=\beta_{0}+\beta_{1} t a x \_d i f f_{i}+\beta_{2} o s \_d_{i}+\varepsilon_{i}
$$

where $n u m_{-}$dif $f_{i}$ is the difference of firm $i$ 's product scope between 2003 and 2004, tax_dif $f_{i}$ is the difference of firm $i$ 's revenue-weighted ETR, ${ }^{8}$ and os_d $_{i}$ is the ownership dummy controlling for the effect of firm-type. The results are in Table 2.

The results after controlling for firm-type imply that firms experiencing larger ETR reduction cut more products.

Next, we estimate a Probit regression to see if higher cost products are more likely to be dropped.

$$
\operatorname{Pr}\left(\text { exit }_{i j}=1\right)=\operatorname{Pr}\left(\beta_{1} r c a_{j}+\beta_{2} \text { tax }_{\_} \text {diff } f_{i}+\beta_{2} \text { os }_{\_} d_{i}+\varepsilon_{i j}>0\right)
$$

\footnotetext{
${ }^{7}$ In the following analysis we only keep the export firms engaging in the ordinary trade in our sample as the firms involving in processing trade might react differently when facing the export rebate changes.

${ }^{8}$ We use the figures in 2004 subtracting the figures in 2003, e.g. num_dif $f_{i}=$ num $_{2004}-$ num $_{2003}$ and tax_diff $f_{i}=\operatorname{tax}_{d}$ if $f_{i}^{2004}-\operatorname{tax}_{d}$ if $f_{i}^{2003}$
} 
Table 2: The Extensive Margin

\begin{tabular}{ccc}
\hline \hline num_diff & Coef & Coef \\
\hline tax_diff & $0.24(0.034)$ & $-0.11(0.033)$ \\
Cons & $-2.39(0.048)$ & $0.16(6.09)$ \\
Control for Ownership & No & Yes \\
\hline
\end{tabular}

Table 3: The Intensive Margin

\begin{tabular}{ccc}
\hline \hline exit & Coef & Coef \\
\hline rca & $-0.19(0.05)$ & $-0.23(0.05)$ \\
tax_diff & $-0.29(0.66)$ & $-0.34(0.65)$ \\
Cons & $-2.49(0.07)$ & $-0.89(0.57)$ \\
Control for Ownership & No & Yes \\
\hline
\end{tabular}

where exit $_{i j}$ is a dummy variable which takes value 1 if the $j$ th product of firm $i$ is dropped, otherwise takes value $0, r c a_{j}$ is the relative comparative advantage index of Chinese firms ${ }^{9}$ which is a proxy for cost parameters $z$, and $t a x_{\_} d i f f_{i}$ and $o s_{-} d_{i}$ are the difference of firm $i$ 's revenue-weighted ETR and the ownership dummies, respectively.

Table 3 reports the results of the Probit regression. It indicates that higher cost products are more likely to be dropped in response to the reduction of ETR. The pattern is line with the model prediction.

\section{Conclusion}

In this paper we extend the seminal work of Nocke and Yeaple (2012) and develop a model to explain how multi-product firms contract their product scope in response to a trade cost increment. When the trade cost increases, firms will drop their less competitive products to release organizational, and reallocate the organizational capital to other products. Our theory

\footnotetext{
${ }^{9}$ This index is given by $r c a_{j}=\left(\frac{x_{i j}}{x_{i}}\right) /\left(\frac{x_{j}}{x}\right)$ where $x_{i j}$ denotes the export product $j$ by country $i, x_{i}$ denotes the total export of country $i, x_{j}$ is the total worldwide export of product $j$, and $x$ represent the total worldwide export. We assume that China is intensive in labor, and the foreign country is intensive in capital. As such the wage is relatively lower in China $\left(w_{l}<w_{m}\right)$ than that in the foreign country $\left(w_{l}^{*}>w_{m}^{*}=w_{m}\right)$. The sectors with larger labor share, $\alpha$, are relatively more competitive (lower $z$ ) than those with lower labor share (higher $z$ ).
} 
is supported by the empirical evidence from China. An important policy implication of the results is that the reduction of the ETR makes export firms drop their less competitive products, which increases firm-level TFP.

\section{Appendix (For Reviewers)}

Proof of (2). A firm minimizes $w_{l} l+w_{m} m$ subject to the constraint $\theta_{\omega} l^{\alpha_{\omega}} m^{1-\alpha_{\omega}}=$ 1. The first-order conditions imply $\frac{m}{l}=\frac{w_{l}}{w_{m}} \frac{1-\alpha_{\omega}}{\alpha_{\omega}}$. The optimal labor and intermediate inputs are

$$
\begin{aligned}
m & =\left(\frac{w_{l}}{w_{m}} \frac{1-\alpha_{\omega}}{\alpha_{\omega}}\right)^{\alpha_{\omega}} \frac{1}{\theta_{\omega}}, \\
l & =\left(\frac{w_{m}}{w_{l}} \frac{\alpha_{\omega}}{1-\alpha_{\omega}}\right)^{1-\alpha_{\omega}} \frac{1}{\theta_{\omega}} .
\end{aligned}
$$

Therefore the minimized cost is $c=z_{\omega} k_{\omega}^{-\theta}$ where $z_{\omega}$ is defined by (3).

Proof of (5). The profit from product $\omega$ is

$$
\begin{aligned}
\pi\left(k_{\omega}, \theta, z_{\omega}\right) & =\left[p\left(k_{\omega}, \theta, z_{\omega}\right)-c\left(k_{\omega}, \theta, z_{\omega}\right)\right] A p\left(k_{\omega}, \theta, z_{\omega}\right)^{-\sigma} \\
& +\left[p^{*}\left(k_{\omega}, \theta, z_{\omega}\right)-c^{*}\left(k_{\omega}, \theta, z_{\omega}\right)\right] A^{*} p^{*}\left(k_{\omega}, \theta, z_{\omega}\right)^{-\sigma} \\
& -f_{\omega} \\
= & \frac{1}{\sigma-1}\left(\frac{\sigma}{\sigma-1}\right)^{-\sigma} \widetilde{A}\left(z_{\omega} k_{\omega}^{-\theta}\right)^{(1-\sigma)}-f_{\omega}
\end{aligned}
$$

where $\widetilde{A}=\left(A+\delta_{\omega} \tau^{1-\sigma} A^{*}\right)$. If the firm exports product $\omega, \delta_{\omega}=1$. Otherwise $\delta_{\omega}=0$. As the profits in the domestic and foreign markets are strictly positive after paying the fixed production cost $f_{\omega}$, the firm will choose to export all products or choose not to export any product. The decision is determined by the entry cost in the foreign market.

Proof of Lemma 1. $\sum k_{\omega}=K_{\theta}$ implies

$$
k_{1}+\left(\frac{\widetilde{z}_{1}}{\widetilde{z}_{2}}\right)^{\frac{1}{(\sigma-1) \theta-1}} k_{1}+\cdots+\left(\frac{\widetilde{z}_{1}}{\widetilde{z}_{N^{*}}}\right)^{\frac{1}{(\sigma-1) \theta-1}} k_{1}=K_{\theta}
$$

Obviously

$$
k_{1}=\frac{K_{\theta}}{Z}, k_{n}=\frac{K_{\theta}}{Z}\left(\frac{\widetilde{z}_{1}}{\widetilde{z}_{n}}\right)^{\frac{1}{(\sigma-1) \theta-1}}
$$


for $n=2, \cdots, N^{*}$, where $Z=\sum_{n=1}^{N^{*}}\left(\frac{\widetilde{z}_{1}}{\widetilde{z}_{n}}\right)^{\frac{1}{(\sigma-1) \theta-1}}$.

When we rank the cost parameter in the form of $z_{1}<\cdots<z_{N}$, the $N^{*}$ th product is of the highest cost parameter among all produced products. The marginal profits obtained from $N^{*}$ th product must be equal to the marginal profits obtained from any other products. Therefore, $N^{*}$ must satisfy (6).

Proof of Lemma 2. For convenience, we denote the product-level profit $\pi\left(k_{\omega}, \theta, k_{\omega}\right)$ by $\pi_{\omega}$ for $\omega \in \Omega$. The expected profit of products $i, j \in \Omega$ are

$$
\begin{aligned}
& E \pi_{i}=\frac{1}{\sigma-1}\left(\frac{\sigma}{\sigma-1}\right)^{-\sigma} \widetilde{A}\left(z_{i} k_{i}^{-\theta}\right)^{(1-\sigma)}-f, \\
& E \pi_{j}=\frac{1}{\sigma-1}\left(\frac{\sigma}{\sigma-1}\right)^{-\sigma} \widetilde{A}\left(z_{j} k_{j}^{-\theta}\right)^{(1-\sigma)}-f,
\end{aligned}
$$

which implies

$$
\frac{E \pi_{i}+f}{E \pi_{j}+f}=\frac{\left(z_{i} k_{i}^{-\theta}\right)^{1-\sigma}}{\left(z_{j} k_{j}^{-\theta}\right)^{1-\sigma}}=\left(\frac{z_{j}}{z_{i}}\right)^{\frac{1-\sigma}{(\sigma-1) \theta-1}}
$$

under (A1). If $z_{i}<z_{j}$, then $\frac{E \pi_{i}+f}{E \pi_{j}+f}>1$ which implies $E \pi_{i}>E \pi_{j}$.

Proof of Lemma 3. Suppose $N^{*}$ is decreasing in $K_{\theta}$. When $K_{\theta}$ increases and $N^{*}$ decreases, (A1) implies $k_{1}$ will increase to $k_{1}^{\prime}$. Then

$$
\widetilde{z}_{N^{*}} k_{N^{*}}^{(\sigma-1) \theta-1} \geq \widetilde{z}_{1} k_{1}^{(\sigma-1) \theta-1}>\widetilde{z}_{1} k_{1}^{(\sigma-1) \theta-1}
$$

The inequality implies that product $N^{*}$ should be produced to maximize the firm's profit. It means $N^{*}$ does not fall when the $K_{\theta}$ increases. By contradiction, $N^{*}$ is increasing in $K_{\theta}$.

Proof of Proposition 1. Let $\Gamma_{\omega} \triangleq \frac{1}{\sigma-1}\left(\frac{\sigma}{\sigma-1}\right)^{-\sigma}\left(z_{\omega} k_{\omega}^{-\theta}\right)^{(1-\sigma)}$. Then $E \pi_{\omega}=$ $\Gamma_{\omega}\left(A+\tau^{1-\sigma} A^{*}\right)-f$. It follows that $\frac{\partial E \pi_{\omega}}{\partial \tau}=-(\sigma-1) \Gamma_{\omega} \tau^{-\sigma} A^{*}<0$. Given $\tau$, for any $i, j \in \Omega$, suppose $z_{i}<z_{j}$. Lemma 2 implies $E \pi_{i}>E \pi_{j}$ or $\Gamma_{i}>\Gamma_{j}$. Let $\tau^{*}$ be defined by $E \pi_{j}=0$ or equivalently $\Gamma_{j}\left(A+\tau^{* 1-\sigma} A^{*}\right)-f=0$. It implies $A+\tau^{* 1-\sigma} A^{*}=\frac{f}{\Gamma_{j}}$. Conditional on $\tau=\tau^{*}$, the expected profit of product $i$ is $E \pi_{i}=\Gamma_{i} \frac{f}{\Gamma_{j}}-f>0$ because of $\Gamma_{i}>\Gamma_{j}$.

Let $\tau$ rise from $\tau_{0}<\tau^{*}$. Initially $E \pi_{i}>0$ and $E \pi_{j}>0$, which imply both of them are kept on average. When $\tau$ rises to $\tau^{*}, E \pi_{i}>0$ and $E \pi_{j}=0$. It follows, on average, that the product $j$ will be dropped and the product $i$ is kept. 
Bernard, A.B., Redding, S.J., Schott, P.K., 2010. Multiple-product firms and product switching. American Economic Review 100, 70-97.

Bernard, A.B., Redding, S.J., Schott, P.K., 2011. Multiproduct firms and trade liberalization. The Quarterly Journal of Economics 126, 1271-1318.

Eckel, C., Neary, P., 2006. Multi-Product Firms and Flexible Manufacturing in the Global Economy. Economics Series Working Papers 292. University of Oxford, Department of Economics.

Fuss, C., Zhu, L., 2012. Comparative advantage, multi-product firms and trade liberalisation : An empirical test. Working Paper Research 219. National Bank of Belgium.

Manova, K., Zhang, Z., 2012. Multi-Product Firms and Product Quality. NBER Working Papers 18637. National Bureau of Economic Research, Inc.

Nocke, V., Yeaple, S.R., 2008. Globalization and the Size Distribution of Multiproduct Firms. Discussion Papers 6948. C.E.P.R.

Nocke, V., Yeaple, S.R., 2012. Globalization and Multiproduct Firms. Discussion Papers 9037. C.E.P.R.

Song, H., Zhu, L., 2011. Comparative Advantage and Multi-product Firms. Working Paper. School of Economics, Zhejiang University. 